\title{
Narrating Change, Voicing Values, and Co-constructing Visions for Intercultural Music Teacher Education
}

\author{
Laura Miettinen, Heidi Westerlund, and Claudia Gluschankof
}

\begin{abstract}
Researchers have suggested that higher education institutions need to be re-thought as 'imagining universities' that continually engage in re-imagining themselves, in order to be able to justify their own existence in a fast-changing world. It can be expected that music teacher education programs, as part of higher education, would benefit from envisioning their shared future from the same starting point. This chapter presents the second-stage inquiry of "Co-creating visions for intercultural music teacher education in Finland and Israel," an ongoing collaborative research project between the Sibelius Academy of the University of the Arts Helsinki and the Levinsky College of Education in Israel. The study is based on the constructionist pre-understanding that music teacher education programs ought to be developed by conversations and collective reflections, and that it is through these reflections that we narrate change. As an overall methodological framework, the study draws from Appreciative Inquiry (AI), emphasizing the positive as the basis from which to envision together what the future of intercultural music teacher education would look like. The data was collected through four workshop discussions, two at each site, totaling 24 participating teacher educators. The forward-looking themes of these second-stage discussions were developed from the groundwork of the first-stage focus group interview inquiry that mapped the present situation. This study suggests that there is an increasing need to create spaces where music teacher candidates and music teacher educators creatively face uncertainty rather than security, and where risk-taking can be encouraged and practiced safely. There is also a need to increase flexibility and openness, and to continue working more collaboratively within the institutions.
\end{abstract}

Keywords Music education · Teacher education · Intercultural · Diversity · Co-construction · Organizational change

\author{
L. Miettinen $(\triangle) \cdot H$. Westerlund \\ Sibelius Academy, University of the Arts Helsinki, Helsinki, Finland \\ e-mail: laura.miettinen@uniarts.fi; heidi.westerlund@uniarts.fi \\ C. Gluschankof \\ Faculty of Music Education, Levinsky College of Education, Tel Aviv, Israel
}

H. Westerlund et al. (eds.), Visions for Intercultural Music Teacher Education, Landscapes: the Arts, Aesthetics, and Education 26,

https://doi.org/10.1007/978-3-030-21029-8_12 


\section{Introduction}

Due to the effects of increasing global mobility and migration, teacher education and schooling worldwide are on the verge of change regarding their approach to diversity. Although multiculturalism as a larger phenomenon has been influencing education for decades, the recent wave of global movement has challenged educational institutions and teacher educators to re-evaluate their curricula and pedagogical approaches. To counteract professional education that relies on tacit knowledge, socialization, and the 'apprentice model,' researchers have suggested that universities and teacher education units should be considered as learning institutions, particularly in such complex matters as engaging with diversity in education (e.g. Ball and Tyson 2011; Jacobowitz and Michelli 2008).

The discussion around cultural diversity has taken different perspectives in previous music education research, such as embracing the value of diverse musical practices (Campbell 2004; Campbell et al. 2005; Schippers 2010; Volk 1998), emphasizing the music teacher's role as a social change agent in culturally responsive teaching in music education (Abril 2013; Lind and McKoy 2016; Robinson, 2006), and understanding social justice in music education (Benedict et al. 2015). In their recent publication, Roberts and Campbell (2015) examine the connections between multiculturalism and social justice in music education by exploring how the five levels of multicultural curriculum reform formulated by J. Banks (2013) can be applied in music education to establish multicultural social action and social justice. However, Westerlund and Karlsen argue that multiculturalism as a dominant ideology of diversity in music education is insufficient, and although it is in many ways beneficial, it also works to "obscure forms of inequality and injustice that fall outside of its conceptual frames" $(2017,80)$. Instead, they offer a more heterogeneous and intercultural approach, which allows for the "development of a wider ethical reflexivity and critical awareness of the paradoxes involved" $(2017,100)$. Similarly, Ballantyne and Mills (2008, 2010, 2015, 2016) have engaged with this area of research through their studies and meta-analyses of research literature on diversity and social justice, in both general teacher education and music teacher education. In addition, Howard et al. (2014) have explored in more detail the process by which the multiculturalism movement has had an influence on the diversification of music teacher education in the United States.

As a response to the need for further scholarly discussion and empirical inquiry into diversity in music teacher education programs, this chapter examines the second-stage inquiry of "Co-creating visions for intercultural music teacher education in Finland and Israel," an ongoing collaborative research project between the Sibelius Academy, University of the Arts Helsinki and the Faculty of Music Education, Levinsky College of Education in Tel Aviv. In 2015, the study became a 
part of the larger cross-national research project "Global visions through mobilizing networks: Co-developing intercultural music teacher education in Finland, Israel, and Nepal." Using the concepts 'mobilizing networks' (Davidson and Goldberg 2010, 13) and 'networked expertise' (Hakkarainen 2013) as theoretical starting points, the Global Visions project explores what future learning institutions would look like if their practices were developed through collaboration, networking, and sharing that increases local and global reflexivity on issues of diversity. Sociopolitically, Finland and Israel are in different phases when it comes to facing the challenges and opportunities created by cultural diversity. In Finland the population structure has only fairly recently started to change toward becoming more culturally diverse due to migration and global mobility whereas in Israel the challenges of promoting peaceful co-existence and social justice between culturally and ethnically diverse populations have been, and are still, a constant feature, even before the state was founded. The collaborative study between the Levinsky College of Education and the Sibelius Academy was initiated based on mutual institutional interest in the co-creation of knowledge and visions for more collaborative and interculturally competent music teacher education, in other words "transorganizational development" (Bouwen and Taillieu 2004; also Gergen 2015, 211).

The first stage of this study mapped the music teacher educators' own intercultural competences, as needed in their work and described by themselves, and the competences their institutions aim to provide. We also asked the music teacher educators to discuss the future needs and challenges on an institutional level, regarding these competences. There have been many attempts in the past to define the concept of intercultural competence (see e.g. Bennett 1993; Byram 1997; Lustig and Koester 2003; Hammer 2015), and here we refer to a definition in Deardorff's (2006) study agreed upon by a group of leading intercultural scholars and administrators: intercultural competence is "the ability to communicate effectively and appropriately in intercultural situations based on one's intercultural knowledge, skills, and attitudes" (2006, 247-248). An intercultural approach in education thus emphasizes the interaction and communication between people from different cultural backgrounds and, aspiring to be interculturally competent, music teacher educators call out the desire to enhance and promote intercultural dialogue and understanding in the music classroom. The first-stage inquiry showed that there is a pressing need for creating opportunities for music teacher educators to discuss and share their experiences on an institutional level, in this case around the topics of diversity and interculturality. The objective of this chapter is to elaborate upon the themes that emerged from the focus-group interviews in the first stage of the study in order to further explore how change is narrated for intercultural music teacher education at the Levinsky College of Education and the Sibelius Academy. 


\section{Theoretical Lenses: Visions for Organizational Change}

The second-stage inquiry presented here is based on the constructionist preunderstanding that music teacher education programs ought to be developed by conversations and collective reflections, and that it is through these reflections that we narrate change. Instead of seeing a teacher education unit simply as a collection of individuals, or as a hierarchical system or place, it is seen as a fluid social collective that constructs shared meanings and understandings (Gergen 2015; Hosking and McNamee 2006). Like in any organization, music teacher educators ought to "create the meaning of work" and "negotiate their visions and goals" together with colleagues (Gergen 2015, 194). When attention is paid to the relational social processes of co-creation, the program can "move creatively with the times" (Gergen $2015,194)$ and "with the conversations in the surrounding culture" $(2015,200)$.

Language, discussion, and stories therefore are seen both as constituents of the organization itself (Gabriel 2015, 275) and as "building blocks" encouraging members to 'think outside the box' (Gergen 2015, 196). In other words, collegial conversation provides a cultural record of not just 'who we are' as a music teacher education unit, but also "what we hope to achieve" (Faber 2002, 21). In the process of discussing and telling stories of our experiences, we add different expressions, we leave out unimportant details and issues we would rather not remember, and we suppress competing voices and conflicting dogma (Faber 2002, 21). Discussions "help us negotiate between those factors that restrict and limit our possibilities and our free ability to pursue our own choices" (Faber 2002, 25). According to the organizational researcher Brenton Faber, this $i$ h how we "narrate change" $(2002,21)$.

Moreover, we assume that music teacher education ought to be developed not just through local discussion, but also global discussion. This study has therefore provided a space for the institutional co-construction of visions, and collectively recognized new possibilities through networking between music teacher educators in two vastly different contexts. By sharing ideas that have been articulated in focusgroup interviews amongst teachers of the music education programs, and by continuing collective discussions, the researchers of this study co-created institutional spaces for conversations to take place; conversations that would not otherwise have been held in the everyday life of the teacher educators. Gergen uses the metaphor of organization as "the co-active flow of conversation" $(2015,199)$, or "conversational co-creation," for a constructionist approach to opening a new way of thinking about organizational change, one in which all workers bring their experiences, knowledge, and values to the table. Here, we would like to add two more spatial metaphors, namely: (1) music teacher education as a "space" for negotiation that reshapes the program, including the pedagogical and curricular space (Barnett 2005, 2011, 77), and (2) music teacher education as a "mobilizing network" of knowledge building (Davidson and Goldberg 2010), in this way highlighting the role of teacher education in knowledge-production. The spaces within the study's two programs can be seen as knowledge-building communities (Westerlund and Karlsen 2017) that, 
through this project, feed discussion both in their local spaces and also across their institutional borders, creating networked knowledge around visions for change in music teacher education.

\section{Research Contexts}

The participants in this study all teach at the music teacher education programs at either the Faculty of Music Education at the Levinsky College of Education in Israel, or the Sibelius Academy in Finland. The two teacher education programs are vastly different, and the study therefore provides maximized opportunities for mutual institutional learning (Stake 1995).

The Sibelius Academy offers a five-and-a-half-year "extended and integrated program" (Zeichner and Conklin 2005, 647) leading to a bachelor's and master's degree in music education, a degree that is required for music teachers in Finnish secondary schools (13-18-year-old students). By holding a master's degree in music education, one is also qualified to teach in other learning institutions such as conservatories and adult learning centers. The program has separate study lines for Finnish and Swedish-speaking students. The program's curriculum includes a wide range of musical genres and styles, including popular music, and emphasizes peer-teaching and -learning practices. Students are selected through an extensive entrance examination process where only approximately $15 \%$ of the over 200 applicants annually are accepted. This means that the level of musicianship among the accepted students is high from the beginning.

In Israel, the educational system supports parallel but separate education systems: state-secular Jewish Hebrew speaking, state-religious Jewish Hebrew speaking, state-Arabic, and state-funded independent schools. Levinsky College belongs to the state-secular Jewish stream; therefore the official teaching language of the institution is Hebrew. At the time of this study's data generation, the Faculty of Music Education at Levinsky College offered four undergraduate programs leading to the certificate required for K-12 teaching: a 4-year B.Ed. program in music education that certifies the students to teach at Hebrew-speaking, state educational institutes, and a 3-year B.Ed. program in music education with three separate study lines in collaboration with other institutions: the Rimon School of Jazz and Contemporary Music, the Ron-Shulamith music school for ultra-orthodox Jewish female students, and the Safed Academic College, where most of the students are Israeli Palestinians who intend to teach in the Arab-speaking schools. About $90 \%$ of applicants are accepted to these programs, and for some of the students these studies offer them their first opportunity to systematically develop their musicianship. The Levinsky music curriculum is mainly based on Western art music and Hebrew singing traditions except in the joint study program with the Safed Academic College, where teachers from Levinsky teach only pedagogical courses and music courses include music from the Arabic tradition. 


\section{Facilitating Institutional Space for Conversational Co-creation: The Research Design of the Study}

As mentioned above, the first-stage inquiry mapped the understandings of and practices for enhancing intercultural competences in the two institutions through focusgroup interviews (see, Miettinen et al. 2018). In the interviews, the music teacher educators discussed cultural responsiveness related to (1) their own and their students' musical style background; (2) the heterogeneity of their students and these students' future students (language, background, religion, abilities, and disabilities); and (3) awareness of formal and non-formal repertoires, and other limitations related to the religiosity of the students. Issues related to curriculum and instruction included the explicit curriculum, especially related to the degree of openness to a variety of musical cultures. Their wishes included more collaboration between colleagues, new courses, the use and place of technology, and their own learning about other musical cultures to be able to include them in the curriculum. Following these discussions, and as part of the first-stage inquiry, four semi-structured interviews were conducted individually with two teacher educators, one from each institution, who had longer experiences of having to step outside their comfort zones when teaching diverse student populations at home and abroad (see Miettinen In print). The two teacher educators were chosen as interviewees because of their input in the first stage group interviews, where they shared their experiences in the discussions. The purpose of these individual interviews was to gain in-depth information on some of the topics that were brought up in the group interviews.

\subsection{The Research Approach: Appreciative Inquiry}

Based on our experiences from the first-stage focus group discussions, we decided that the second stage of discussions would be inspired by Cooperrider and Srivastva's (1987; Cooperrider et al. 2008) appreciative inquiry approach, with its premise that "appreciative narratives unleash the powers of creative change" (Gergen 2015, 205). Appreciative Inquiry (AI) emphasizes the positive past and present as the grounds upon which a group or organization can envision what the future could look like. AI has been described as a "generative learning process that uncovers narratives of success and builds upon them" (Ridley-Duff and Duncan 2015, 1580). According to Cooperrider et al. (2008), AI's "aim is to generate new knowledge of a collectively desired future" (2008, xi). The research process of AI includes four stages of inquiry: "discovery, dream, design, and destiny." The first stage of this study was "discovery," where the participants engaged in dialogues and shared their views on the positive aspects of the program, particularly what works and what is valuable regarding their work. These discoveries were then cultivated in the "dream" stage, where the participants started to envision "a desired future" for their program, asking what possibilities there might be to further develop the present situation (2008, 
5-7). Since the first two stages of "discovery" and "dream" are more researcher-led, and thus easier to facilitate and control by the researchers than the latter two, we decided at this point to carry out only these first two stages in order to test the approach in practice.

Altogether four workshops were held, two at each site, with a total of 24 participants. We designed the AI workshops in three parts: (1) introduction; (2) smallgroup discussions; (3) reports and whole group discussion. The aim of the half-hour introduction (given by the first author of this study) was to present the preliminary findings of the first-stage focus-group interviews from both countries. For the second part, the participants were asked to divide into two to three small groups to discuss among themselves, in their own language, the four questions (sent via email prior to the workshop) based on AI-models: (1) What do you see as the core values of your institution, and how are these values articulated and communicated to you as a staff member? (2) If you were to imagine the future of your own institution with respect to the changes occurring in the surrounding diverse society, what would the main challenges be? (3) What qualities would the next generation of music teachers/ music-teacher educators need? And (4) If you had three wishes for your institution regarding how to address cultural diversity in the music education program, what would they be? The nature of the small-group discussions was not primarily researcher-participant interviews, as in the first-stage study, but rather shared discussions between the colleagues, facilitated by the researchers. This part lasted between 45 and $60 \mathrm{~min}$. The third part gathered all the participants together, where each of the small groups reported their discussions to the other groups and researchers. These small-group reports were followed by a joint reflection period. The researchers recorded the small-group reports and the subsequent joint reflections; these recordings comprise the data set of this second-stage study.

\subsection{Limitations of the Second-Stage Inquiry}

The data has limitations in terms of whose voices are represented. The groups of participating teacher educators were relatively small, and a wider range of ideas could have been generated if more opportunities for discussion would have been organized. Moreover, a group discussion that is reduced into a summarizing report, presented by one person, is naturally limited in terms of how individual ideas are finally given space. The negotiation that took place during the small-group discussions, and the potential disagreements between the teachers, did not necessarily end up in the data as such. Furthermore, there were clear limitations due to language preferences. In both contexts, there were teacher educators who were not confident in expressing their ideas in English. However, as the questions were sent to the participants beforehand, the data brings out ideas that the teacher educators had already reflected upon before the workshop; it was thus of their own volition that they wanted to discuss these ideas together with their colleagues, and during the smallgroup discussions they were also able to converse in the language in which they 
usually communicate at their institution. Despite these limitations, the data provides us with valuable insights on how the music teacher educators perceived their institutions, their own roles within the institutions, and the organizational future in terms of diversity.

\section{Research Question and Data Analysis}

The question that we posed for the second-stage inquiry and the data was: How is change narrated in music teacher educators' conversational co-creation for intercultural music teacher education at the Levinsky College of Education and the Sibelius Academy? In our analysis, we applied a process of "narrative creation" (Bold 2012, 148) in which the different accounts in the data were first organized based on how they fit together with each other, and then in the next stage based on how they "made the narrative flow" $(2012,148)$. We wanted the "representative constructions" $(2012,153)$ to include the variety of views and experiences from both institutions, without comparisons being made between them. The shared voice of "we" is not to be understood as a unison, nor to be representative of all people who participated the interviews, but rather to "act more as examples of experiences from different perspectives" $(2012,153)$, yet interpreted as "the professional voice." The constructions include data from both contexts and all group interviews, and is predominantly composed through direct data quotations with no preliminary categories or themes. By following the ethos of AI, the analysis aimed at uncovering "narratives of success" (Ridley-Duff and Duncan 2015, 1580) by constructing the full spectrum of ideas, along with the potential tensions, on how music teacher education programs could be developed to better respond to issues of diversity. The co-constructed representations that condense the data are thus not aiming to represent reality as such in the two contexts, but rather the reality of ideas and ideologies, as co-created through the discussions and collectively conducted analysis.

The 'conversational co-construction' of this study has taken place at various levels: the workshop discussions were fueled by our main findings from the first-stage focus group discussions held at both institutions, as well as by other studies in the larger project. In the second-round workshops, teacher educators had a chance to discuss their individual views in a smaller group, and to formulate shared ideas together with their colleagues. The group reports can be seen as compromises, with any disagreements faded into the background; however, they also created further discussion that likewise informed our data. In this way, the discussions had several layers of co-construction. Importantly, our analysis adds one more layer of coconstruction, as we selected and combined ideas from the data by blending the collective and individual voices in the reports of the two institutional contexts.

The co-constructed narratives that were created through the bottom-up principle can be seen to cover two larger thematic areas, namely, how to deal with uncertainty related to diversity, and how to better support the development of a collaborative institutional mindset. For the purpose of presenting the findings of the analysis, we 
have divided the two thematic areas into four emerging themes: problematizing endless diversity; addressing flexibility and openness as desired qualities for both music teacher education and future music teachers; envisioning music teacher education as a space for the pedagogical co-construction of knowledge; and change through collegial dialogue and sharing.

\title{
6 Living in 'Epistemological Pandemonium'
}

\subsection{Problematizing Endless Diversity}

In an expert culture, 'super-diversity' (Vertovec 2007) and 'supercomplexity' (Barnett 2000) appear as problems when too many knowledges fight over the educational space. The music teacher educators discussed questions such as: how is specialization related to the core value of versatility, and how could such values guide the pedagogical and musical underpinnings in a music education program? The term of the "Renaissance man" was used to describe the envisioned contesting qualities and demands of the next-generation music teacher and music teacher educator. As a solution, an important distinction was made between expertise and versatility at the program level, on the one hand, and versatility as an aspired competence at the individual student teacher's level, on the other hand.

\begin{abstract}
Multiculturalism keeps coming up as an issue. There is always a desire to do something about it. How do we deal with that as teachers? How diverse can we be and still maintain a good, high level? We can't all be an expert in African and Cuban and Indian music. The issue is, what does it mean to be an expert? Multiculturalism might be mediocrity. So that's not what we want. We think that we need to have courage and take the best students and the best teachers. It raises the level. The curriculum of the program has to be multicultural, but not every teacher [in teacher education] has to be multicultural. That's why we have several teachers - numerous teachers, because no-one could teach everything. Our job as teachers is maybe helping the student to construct some kind of meta-knowledge about the ways in which they make music.
\end{abstract}

Inclusion of diverse values touches upon the question of value relativism, and the limits of music teachers' cultural identity.

It's an interesting discussion, whether there is a music teacher mentality in terms of cultural diversity. Are we kind of expecting that everybody has to tolerate as much as possible? And is it realistic or not?

This discussed notion of tolerance can be interpreted through the 'dilemma of multiculturalism' that divides the world into cultural wholes, and takes all possible diversities as positive. This phenomenon has been discussed, for instance, by Zygmunt Bauman, who argues that when mutual tolerance is combined with mutual indifference, "cultural communities may live in close proximity but they will rarely speak to one another" $(2011,59)$. According to Bauman, "A 'multicultural' world allows cultures to coexist, but the politics of 'multiculturalism' does not make it 
easier, indeed possibly makes it more difficult, for these cultures to gain benefits and enjoyment from their coexistence" (ibid).

Teachers identified the importance of entrance examinations in hindering diversity in the student population. The academic frame was considered as setting the criteria for who is accepted in music teacher education, and how those selections are made.

And does that actually reflect the entrance examinations?

You're leaving so many people out who are wonderful musicians.... But then it's an academic institution. We cannot base our teaching on intuition and experience.

This also raises the question of teacher educators' need for security. Instead of accepting students from different musical traditions and cultural backgrounds into their programs, and in that way challenging themselves to think differently and strive for versatility in their teaching, an institution's "quality requirements" can be used as an excuse to avoid the hard work of stepping out of one's comfort zone as a teacher.

\subsection{Addressing Flexibility and Openness as Desired Qualities for Music Teachers}

Dealing with uncertainty requires risk-taking, flexibility, and openness. Whilst examining the challenges of higher education in 'supercomplex societies', Barnett (2000) argues that there is an urgent need for universities to generate uncertainties and self-reflexivity. Students graduate and are then forced to grasp unpredictable intersections of knowledges, and they must not be afraid of either uncertainty or making daring interventions $(2000,167)$. Paradoxically, this occurs at the same time universities and higher education need to help "to assuage that uncertainty" and "to multiply accounts of the world" (Barnett 2011, 123). How higher music education can provide spaces for students to face uncertainty, whilst at the same time multiplying accounts that assuage that uncertainty, seems an essential question to reflect upon in music teacher education. Here, the teachers' reflections pointed out that being prepared for facing uncertainty can mean that one's vision is open and free from fixed answers.

It's really important that we could share some of the weird situations that we face, that they don't stay in the classroom. Then it helps everyone to build up the vision that anything can happen, but you just have to resolve the situation without considering all the possible options beforehand. That's usually what students ask: they want to have those manuals. But there aren't those kinds of practical manuals; they don't exist. And you don't need them, you just need to learn how to be interested, listen, and meet every student. 
Envisioning flexibility and openness again took place on two levels: the need to make the curriculum of music teacher education more flexible and open, and the vision of future music teachers being able to meet the needs of an ever-changing society. The program level flexibility was related to the basic assumptions that frame the program.

Are we an institution that is about transmitting a musical culture? Keeping it alive for the next generation. Is that maybe a core value? The challenge may not be breaking a hegemony, 'cause maybe there isn't one, but maybe rethinking them. Maybe we need to reframe core courses. Every kind of action that rocks the boat is good and is needed. We need to be courageous enough to take true risks and to see what happens, and that is needed with the changes that cultural diversity is bringing to us. Is it true that you need to begin with Western classical? Is that the very beginning, so to speak? But who said Gamelan doesn't have pedagogies, or is not systematic.

Even when a music teacher education program involves plenty of options and musical diversity, these options may not encourage the student teachers to develop their self-reflexivity toward cultural diversity by forcing them to step out of their comfort zones. The idea of obligatory engagement with issues of diversity arose as an identified need for program-level change.

We talked about openness and listening - opening up to the new and reaffirming the old. Being able to absorb new ideas. Also, in terms of interhuman relationships. And the flexibility to absorb other musical contexts and contents. We talked about adaptability, and about the ability to identify the musical elements within different genres. And situations where anything can happen. You need to just go out there, and then you just survive, facing these new situations. It's a capability to communicate outside your own competence, outside your own comfort zone and your own field. In teacher training, that could be fortified, for example by encouraging students to follow the news, to be active, to be activists.

When discussion moves to the realm of the 'strange,' 'different,' or 'unknown,' teaching-learning processes can then be constructed as spaces for risk-taking - both for teachers and students. MacPherson (2010) emphasizes that such "safe" spaces in diverse educational contexts are not simply places to represent one's culture or identity, as in the multicultural education approach, but spaces in which constant discussions should be encouraged, and where students should be allowed to make mistakes and practice how to interact or respond $(2010,279)$. Opening up these shared spaces or 'third spaces' (Bhabha 1994) can become places "where all the existing practices and conceptions ... can be left behind in order to come up with new understandings and ways of interacting" (Miettinen In print). In these spaces, supporting the student's autonomy becomes equally important as embracing diversity. Consequently, music teacher educators need to learn to live in an 'epistemological pandemonium' where risk-taking and openness, on the one hand, and stability and safety, on the other hand, can co-exist enabling a shared space for creative interaction. 


\title{
7 Co-construction of Knowledge as an Institutional Mindset
}

\subsection{Envisioning Music Teacher Education as a Space for Pedagogical Co-construction of Knowledge}

Teacher educators pondered the ways that they could support students taking part in pedagogical knowledge creation. Encouraging risk-taking and cultivating openness and sensitivity toward diversity were seen as necessary means in this endeavor, although it was hard for them to pinpoint particular ways to do this in class.

\begin{abstract}
We thought that the task of the teachers is to support the student while she finds her own pedagogical path, and in that all the values of being open, of being sensitive. We need to support teachers and students to be courageous and to take risks, both artistically and pedagogically. But it's really difficult to give any practical advice about how to do this. However, we can all individually affect the general atmosphere, of not only tolerating but embracing cultural diversity. It can happen in really, really small things, in small, small steps, and they can all build this atmosphere. Also, we construct reality at the same time as we talk, depending on what kind of words we use.
\end{abstract}

Teachers identified one common way to respond to diversity, namely, learning from each other.

\begin{abstract}
One core value is flipped learning. ${ }^{1}$ That the teacher supports the autonomy of the pupil. And the whole idea is that you learn in a group. And the basic question in this kind of group activity is what good can you do for the others via your own learning.

Yesterday, for the first time, I took them [the students] down to the practice room. They've never been. And they walked into the practice room like children into a candy store.... Here I am sitting, I'm the teacher. But I'm totally in the corner. And I'm letting them make their music. Now in doing this I'm observing the ways in which they make music, and their concept of music teaching and learning, because they're teaching each other and they're learning.... In this way, I'm letting them make music as they know how to make music.... And my job as a teacher here, is maybe helping them construct some kind of meta knowledge ... about the ways in which they are making music. As a teacher I will learn, and I will maybe be able to implement some ideas from this later in my career.
\end{abstract}

As the findings of our first-stage inquiry showed (Miettinen et al. 2018), the teacher educators expressed a willingness to learn from and with the students, for instance in situations where the teacher educator did not speak or understand the mother tongue of the students or did not have enough knowledge about the students' musical tradition. The teacher educators' accounts in both data sets reinforce the view that 'learning from each other' (Darling-Hammond and Lieberman 2012) can be an effective way to respond to the everyday challenges created by cultural diversity in

\footnotetext{
${ }^{1}$ In the pedagogical approach of flipped learning, the traditional teacher-centered model shifts to a learner-centered approach as the students are actively involved in knowledge construction when the opportunity to access the learning material before the class allows the in-class time to be "dedicated to exploring topics in greater depth and creating rich learning opportunities" (Flipped Learning Network, 2014).
} 
a classroom context. This mutual learning can happen both within and across institutions, given favorable circumstances.

\subsection{Initiating Change Through Collegial Dialogue and Sharing}

Considering that engaging in conversation, talking aloud, and reflecting together with your peers is a common practice in teacher education, this study highlights that this very same practice of facilitating conversation is equally important amongst the teacher educators themselves, when aiming at professional development. Similarly, as teacher education programs should provide their students spaces for thinking out loud and sharing their experiences, and in this way develop future teachers' reflexivity (e.g. Juntunen and Westerlund 2013; O'Connell Rust 2002), the staff members also need these spaces in order to develop themselves and enhance "institutional learning" (Senge 2006). This paradoxical difference between classroom practices and organizational practices came out in discussions, as the teacher educators called for more opportunities to meet, discuss, and share their experiences. The teachers had several suggestions for how to enhance collaboration, and how to prepare not just their students, but also themselves, for culturally diverse teaching situations.

\footnotetext{
We envisioned an institution where the dialogue is part of it. Dialogue among all the teachers, and also with other institutions. We want to create a dialogue. People do not seem to meet enough. We talked about the personal experiences; how the teachers in different music genres don't necessarily meet or hear each other, and also that there are not enough opportunities to even have these meetings. This is the opposite of segregation. We've been talking about doing mutual concerts. Meeting each other in its creative power. Teachers playing together. We talked about how to teach collaborative courses and interdisciplinary courses, to work together to produce books. Teachers developing teaching programs together. We were talking about using a website as a platform.
}

Part of the conversation involved realizing that a reflective community in music teacher education does not need to be a harmonious whole, and that discussion, indeed, is related to change.

So, basically, the community changes, constantly. We constantly change. So, it's a neverending story. But it needs to be done in respectful ways, and by giving space to other opinions, and we don't have to agree. Why can't we create such a dialogue within our program? Why do we need people to be so far away to talk freely? If we are talking together, everyone has an agenda.

As Faber writes, "change can be a stabilizing and recursive force as an organization's stories pull discordant images and narratives back into a sense of temporary alignment" $(2002,39)$. In this way, change is "rarely associated with unity, continuity, or agreement" (ibid.). The key, then, is to be aware of how disagreeing views and opposing arguments can be included in the same space, conversation, and process. More importantly, however, during the discussions the teachers realized, as Gergen argues, that "major shifts in the organization can be achieved just through talking!" 
and that such dialogic practices can become a "major game changer" (Gergen 2015, 206). At the Sibelius Academy, the discussion did indeed continue, and later resulted in a decision to include sensitivity to cultural diversity as one of the goals that is expected to permeate all subjects in the new music teacher education curriculum.

\section{Concluding Thoughts}

Researchers have suggested that higher education institutions need to be re-thought as 'imagining universities' (Barnett 2011) that continually engage in re-imagining themselves, in order to be able to justify their own existence in a fast-changing world. In the same way, it has been suggested that teacher education programs need to be re-imagined from the perspective of moving away from a curriculum focused on teachers' knowing, and towards a curriculum organized around what teachers need to be able to do. It can be expected that music teacher education programs, as part of higher education, would benefit from envisioning their shared future from the same starting point.

To conclude, this study suggests that there is an increasing need to create spaces where music teacher candidates and music teacher educators creatively face uncertainty rather than security, and where risk-taking could be encouraged and practiced safely. More discussion and the sharing of thoughts, emotions, and fears regarding issues of diversity in teaching could make it easier to handle the ambivalence between resistance and openness to change. There is also a need to increase flexibility and openness, and to continue working more collaboratively within the institutions. Moreover, if institutional collaboration is taken seriously in developing future music teacher education, this also has consequences for how leadership in music teacher programs ought to be understood. Conversational co-creation requires "relational leading" of the flow of conversation to generate, sustain, and create the meanings that can move the organization forward, as the relational processes become a focus of concern (Gergen 2015, 199). The effort put into the co-creation of visions pays itself back, as people tend to support what they create $(2015,203)$. Also, coming back to Faber's idea of the potential of collegial conversations, co-constructed understandings of 'who we are' as music teacher educators, staff members, and as a music teacher education unit paves the way for envisioning together 'what we hope to achieve' (Faber 2002, 21). Judging by the many comments from the participants on how the discussions initiated by this study should be continued, the need for sharing and co-creating within their programs is great. Unveiling that need and developing the collaboration further are the central goals of the whole "Global visions through mobilizing networks" project. The study presented in this article has aimed to facilitate the envisioning process within and across the two participating institutions, with a vision that the re-imagining and collaboration would continue to re-shape the ways that music teacher education responds to the challenges of cultural diversity as part of our rapidly changing world. 
Acknowledgements This publication has been undertaken as part of the Global Visions through Mobilizing Networks project funded by the Academy of Finland (project no. 286162).

\section{References}

Abril, C. R. (2013). Toward a more culturally responsive general music classroom. General Music Today, 27(1), 6-11.

Ball, A. F., \& Tyson, C. A. (2011). Preparing teachers for diversity in the twenty-first century. In A. F. Ball \& C. A. Tyson (Eds.), Studying diversity in teacher education (pp. 399-416). Lanham: Rowman \& Littlefield.

Ballantyne, J., \& Mills, C. (2008). Promoting socially just and inclusive music teacher education: Exploring perceptions of early-career teachers. Research Studies in Music Education, 30(1), 77-91.

Ballantyne, J., \& Mills, C. (2015). The intersection of music teacher education and social justice: Where are we now? In C. Benedict, P. Schmidt, G. Spruce, \& P. Woodford (Eds.), The Oxford handbook of social justice in music education (pp. 644-657). New York: Oxford University Press.

Banks, J. A. (2013). Approaches to multicultural curriculum reform. In J. A. Banks \& C. A. M. G. Banks (Eds.), Multicultural education: Issues and perspectives, 8th ed. (pp. 181-199). Hoboken: Wiley.

Barnett, R. (2000). University knowledge in an age of supercomplexity. Higher Education, 40(4), 409-422.

Barnett, R. (2005). Concluding note. In R. Barnett (Ed.), Reshaping the university. New relationships between research, scholarship and teaching (pp. 192-193). Berkshire: Open University Press.

Barnett, R. (2011). Being a university. London: Routledge.

Bauman, Z. (2011). Culture in a liquid modern world. Malden: Polity Press.

Benedict, C., Schmidt, P., Spruce, G., \& Woodford, P. (2015). The Oxford handbook of social justice in music education. New York: Oxford University Press.

Bennett, M. J. (1993). Towards ethnorelativism: A developmental model of intercultural sensitivity. In R. Michael Paige (Ed.), Education for the intercultural experience (2nd ed. pp. 21-71). Yarmouth: Intercultural Press.

Bhabha, H. K. (1994). The location of culture. London: Routledge.

Bold, C. (2012). Using narrative in research. London: Sage Publications.

Bouwen, R., \& Taillieu, T. (2004). Multi-party collaboration as social learning for interdependence: Developing relational knowing for sustainable resource management. Journal of Community and Applied Social Psychology, 14, 137-153.

Byram, M. (1997). Teaching and assessing intercultural communicative competence. Clevedon: Multilingual Matters.

Campbell, P. S. (2004). Teaching music globally: Experiencing music, expressing culture. New York: Oxford University Press.

Campbell, P. S., Drummond, J., Dunbar-Hall, P., Howard, K., Schippers, H., \& Wiggins, T. (Eds.). (2005). Cultural diversity in music education: Directions and challenges for the 21st century. Bowen Hills: Australian Academic Press.

Cooperrider, D. L., \& Srivastva, S. (1987). Appreciative inquiry in organizational life. In R. W. Woodman \& W. A. Pasmore (Eds.), Research in organizational change and development (Vol. 1, pp. 129-169). Stamford: JAI Press.

Cooperrider, D. L., Whitney, D., \& Stavros, J. M. (2008). The appreciative inquiry handbook: For leaders of change (2nd ed.). Brunswick: Crown Custom Publishing. 
Darling-Hammond, L., \& Lieberman, A. (2012). Teacher education around the world: What can we learn from international practice? In L. Darling-Hammond \& A. Lieberman (Eds.), Teacher education around the world. Changing policies and practices (pp. 151-169). London: Routledge.

Davidson, C. N., \& Goldberg, D. T. (2010). The future of thinking. Learning institutions in a digital age. London: MIT Press.

Deardorff, D. K. (2006). Identification and assessment of intercultural competence as a student outcome of internationalization. Journal of Studies in International Education, 10, 241-266.

Faber, B. D. (2002). Community action and organizational change: Image, narrative, identity. Carbondale: Southern Illinois University Press.

Flipped Learning Network (FLN). (2014). What is flipped learning? [PDF file]. Retrieved from: https://flippedlearning.org/wp-content/uploads/2016/07/FLIP_handout_FNL_Web.pdf

Gabriel, Y. (2015). Narratives and stories in organizational life. In A. De Fiona \& A. Georgakopoulou (Eds.), The handbook of narrative analysis (pp. 275-292). Oxford: Wiley Blackwell.

Gergen, K. J. (2015). An invitation to social construction (3rd ed.). London: Sage.

Hakkarainen, K. (2013). Expertise, collective creativity, and shared knowledge practices. In H. Gaunt \& H. Westerlund (Eds.), Collaborative learning in higher music education (pp. 13-26). London: Ashgate.

Hammer, M. R. (2015). Intercultural competence. In J. M. Bennett (Ed.), The SAGE encyclopedia of intercultural competence (pp. 483-485). London: Sage Publications.

Hosking, D. M., \& McNamee, S. (Eds.). (2006). The social construction of organization. Copenhagen: Copenhagen Business School Press.

Howard, K., Swanson, M., \& Campbell, P. S. (2014). The diversification of music teacher education: Six cases from a movement in progress. Journal of Music Teacher Education, 24(1), 26-37.

Jacobowitz, T., \& Michelli, N. M. (2008). Diversity and teacher education: What can the future be? In M. Cochran-Smith, S. Feiman-Nemser, D. John McIntyre, \& K. E. Demers (Eds.), Handbook of research on teacher education. Enduring questions in changing contexts (3rd ed., pp. 679-685). New York: Routledge.

Juntunen, M-L., \& Westerlund, H. (2013). Laadukas arviointi osana oppimista ja opetusta [Highquality assessment as part of learning and teaching] In Musiikkikasvattaja: kohti reflektiivistä käytäntöä [Music educator: Toward reflexive practice.] (Eds.), M-L. Juntunen, H. M. Nikkanen, \& H. Westerlund (pp. 71-92). Jyväskylä: PS-Kustannus.

Lind, V. R., \& McKoy, C. L. (2016). Culturally responsive teaching in music education. From understanding to application. New York: Routledge.

Lustig, M. W., \& Koester, J. (2003). Intercultural competence: Interpersonal communication across cultures (4th ed.). Boston: Allyn \& Bacon.

MacPherson, S. (2010). Teachers' collaborative conversations about culture: Negotiating decision making in intercultural teaching. Journal of Teacher Education, 61(3), 271-286.

Miettinen, L. (In print). Religious identities intersecting higher music education: An Israeli music teacher educator as boundary worker. In A. A. Kallio, P. Alperson, \& H. Westerlund (Eds.), Music, education, and religion: Intersections and entanglements. Bloomington: Indiana University Press.

Miettinen, L., Gluschankof, C., Karlsen, S., \& Westerlund, H. (2018). Initiating mobilizing networks: Mapping intercultural competences in two music teacher programmes in Israel and Finland. Research Studies in Music Education, 40(1), 67-88. https://doi.org/10.1177/13211 $03 X 18757713$.

Mills, C., \& Ballantyne, J. (2010). Pre-service teachers' dispositions towards diversity: Arguing for a developmental hierarchy of change. Teaching and Teacher Education, 26(3), 447-454.

Mills, C., \& Ballantyne, J. (2016). Social justice and teacher education: A systematic review of empirical work in the field. Journal of Teacher Education, 67(4), 263-276. 
O'Conell Rust, F. (2002). Professional conversations: New teachers explore teaching through conversation, story, and narrative. In N. Lyons \& V. K. LaBoskey (Eds.), Narrative inquiry in practice. Advancing the knowledge of teaching (pp. 173-188). New York: Teachers College, Columbia University.

Ridley-Duff, R. J., \& Duncan, G. (2015). What is critical appreciation? Insights from studying the critical turn in an appreciative inquiry. Human Relations, 68(10), 1579-1599.

Roberts, J. C., \& Campbell, P. S. (2015). Multiculturalism and social justice. Complementary movements for education in and through music. In C. Benedict, P. Schmidt, G. Spruce, \& P. Woodford (Eds.), Oxford handbook of social justice in music education (pp. 272-286). New York: Oxford University Press.

Robinson, K. M. (2006). White teacher, students of color: Culturally responsive pedagogy for elementary general music in communities of color. In C. Frierson-Campbell (Ed.), Teaching music in the urban classroom. A guide to survival, success, and reform (pp. 35-56). Lanham: Rowan \& Littlefield Education.

Schippers, H. (2010). Facing the music: Shaping music education from a global perspective. New York: Oxford University Press.

Senge, P. M. (2006). The fifth discipline: The art and practice of the learning organization (2nd ed.). London: Random House.

Stake, R. E. (1995). The art of case study research. Thousand Oaks: Sage.

Vertovec, S. (2007). Super-diversity and its implications. Ethnic and Racial Studies, 30(6), $1024-1054$.

Volk, T. M. (1998). Music education and multiculturalism: Foundations and principles. New York: Oxford University Press.

Westerlund, H., \& Karlsen, S. (2017). Knowledge production beyond local and national blindspots: Remedying professional ocularcentrism of diversity in music teacher education. Action, Criticism and Theory for Music Education, 16(3), 78-107.

Zeichner, K. M., \& Conklin, H. G. (2005). Teacher education programs. In M. Cochran-Smith \& K. M. Zeichner (Eds.), Studying teacher education: The report of the AERA panel on research and teacher education (pp. 645-735). Mahwah: Lawrence Erlbaum Associates for AERA, Washington, DC.

Open Access This chapter is licensed under the terms of the Creative Commons Attribution 4.0 International License (http://creativecommons.org/licenses/by/4.0/), which permits use, sharing, adaptation, distribution and reproduction in any medium or format, as long as you give appropriate credit to the original author(s) and the source, provide a link to the Creative Commons licence and indicate if changes were made.

The images or other third party material in this chapter are included in the chapter's Creative Commons licence, unless indicated otherwise in a credit line to the material. If material is not included in the chapter's Creative Commons licence and your intended use is not permitted by statutory regulation or exceeds the permitted use, you will need to obtain permission directly from the copyright holder.

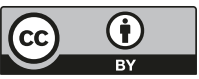

